\section{Prevalence of intestinal parasitic infection of kindergarten children}

\section{Maharjan $\mathrm{R}^{1}{ }^{1}$ Timilshina $\mathrm{M}^{1,2^{*}}$ Shakya $\mathrm{R}^{1}{ }^{1}$ Bhattarai S, ${ }^{1}$ Bhattarai S, ${ }^{1}$ Gurung $P^{1}$}

${ }^{1}$ St. Xavier's College, Maitighar, Kathmandu, Nepal, ${ }^{2}$ Genesis Laboratory and Research Center, Kathmandu, Nepal

*Correspondence to: Mr. Maheshwor Timilshina, St. Xavier's College, Maitighar, Kathmandu, Genesis Laboratory and Research Center, Ghatthaghar, Bhaktapur, Nepal, email: timelsena@hotmail.com, Tel. No: (+977)-9841787943

\begin{abstract}
INTRODUCTION: Intestinal parasitic infections are the major public health problems of Nepal. Apart from causing mortality and morbidity, infection with intestinal parasites has been associated with stunting of linear growth, physical weakness and low educational achievement in school children. The drinking water is considered as the major cause for parasitic infection. This study aims to determine the prevalence of parasitic infection among the children visiting kindergarten of the Kathmandu, Khusibhu area.
\end{abstract}

METERIALS AND METHODS: Cross sectional study was done in randomly selected Kindergarten of Khusibhu area. A total of 101 samples were examined. The study was focused in isolating intestinal parasites using normal saline and iodine wet mount method. Both macroscopic and microscopic studies were performed.

RESULTS: Among the samples 45.5\% $(\mathrm{n}=46)$ showed parasitic infection in which the Giardia lambia infection was found the highest $56.5 \%$ $(\mathrm{n}=26)$ and infection with Ascaris lumbricoides was found lowest $8.7 \%(\mathrm{n}=4)$. Infection rate was found to be high in children drinking filtered water than among those drinking boiled and filtered water.

CONCLUSION: The prevalence of parasitic infection in children is mainly associated with hygiene and food habit of the children. Hence good education about the hygienic practice helps in the prevention of the infection.

KEY WORDS: Intestinal parasites, Drinking water, Children

Article submitted 3 July. Reviewed 25 August. Author correction 27 August. Final version accepted 12 September 2013. 
Intestinal parasitosis is one of the foremost causes of public health troubles in the developing countries like Nepal. ${ }^{1}$ In Nepal, morbidity and mortality rate is found high among children below the age of 5 years, due to consumption of contaminated water. ${ }^{2}$ waterborne diseases are the most recent emerging infectious disease which contribute $70-80 \%$ health problem on the developing countries. ${ }^{3}$ The reported prevalence of intestinal parasites varies considerably from one study to another. Infection has principally been ascribed to the inappropriate sanitary habit, absence of safe and pure drinking water, unmanaged fecal disposal system, poor socioeconomic condition and wide distribution of parasites contained in the environment. 4,5 Though frequent, these infections are not always trivial. They can be the cause of a wide clinical spectrum ranging from apparently symptomless infections to severe conditions. ${ }^{6,7}$ A number of studies focusing on intestinal parasites were done in different community groups such as preschool children, schoolchildren in Nepal. In line with this, interventions were undertaken to minimize the burden. This study was conducted to determine the prevalence of intestinal parasites among the students going kindergarten school.

The study was carried out at Department of Microbiology, St. Xavier's College, Maitighar from $31^{\text {st }}$ August 2011 to $20^{\text {th }}$ October 2011 . With the consent of school authority the school children were given the brief description about the importance of the stool examination to detect the parasite. Dry and clean labeled plastic container was distributed and instructed them to bring a spoonful stool sample next morning. Each stool sample was examined macroscopically for its consistency (formed, semi formed, unformed), the presence of blood, mucus, color and worms and/or segments of parasites. Microscopic observation was done by using normal saline and iodine solution and observed first at low power $(10 x)$ followed by high power $(40 x)$ of the microscope, for the detection of oocytes, cysts and trophozoites of protozoa and the detection of the larvae or the eggs of helminthes. The findings were analyzed statistically by using Chi square test.

Out of 101 samples, $45.5 \%(n=46)$ were found to be infected. The incidence of infection in male children $(49.2 \%)$ was slightly higher than in female children (40.5\%). Parasitic infection among children drinking raw water was found highest whereas those consuming boiled and filtered was lowest.
Table 1. Relation between drinking habit and parasitic infection

\begin{tabular}{|c|c|c|c|c|c|c|}
\hline \multirow{3}{*}{$\begin{array}{l}\text { Drinking } \\
\text { habit }\end{array}$} & \multicolumn{4}{|c|}{ Number of individual } & \multirow{3}{*}{ Total } & \multirow{3}{*}{$\chi^{2}$} \\
\hline & \multicolumn{2}{|c|}{$\begin{array}{l}\text { With } \\
\text { parasite }\end{array}$} & \multicolumn{2}{|c|}{$\begin{array}{l}\text { Without } \\
\text { parasite }\end{array}$} & & \\
\hline & $\mathrm{n}$ & $\%$ & $\mathrm{n}$ & $\%$ & & \\
\hline Boiled & 2 & 10 & 18 & 90 & 20 & \\
\hline Filtered & 17 & 85 & 3 & 15 & 20 & \\
\hline Raw & 22 & 63 & 13 & 37.1 & 35 & \\
\hline $\begin{array}{l}\text { Boiled and } \\
\text { filtered }\end{array}$ & 1 & 6.6 & 14 & 93.3 & 15 & 36.487 \\
\hline Jar & 4 & 36.4 & 7 & 63.6 & 11 & \\
\hline Total & 46 & & & & 101 & \\
\hline
\end{tabular}

Among the infected samples Giardia lambia infection was found the highest, 56.5\% $(n=26)$ and infection with Ascaris lumbricoides was found to be lowest, $8.7 \%(n=4)$.

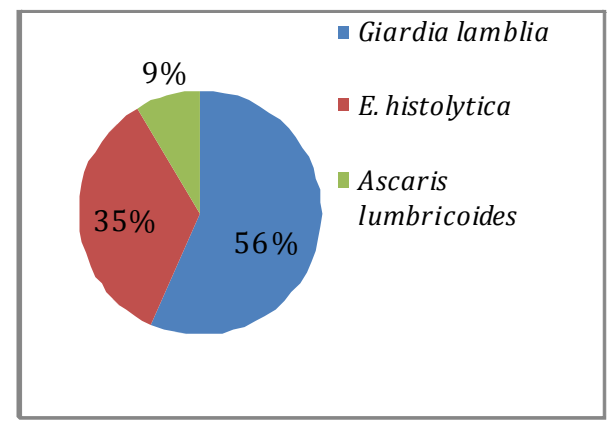

Figure1. Total parasite count among infected samples.

Similar results of Male Children showing higher incidence rate $(49.2 \%)$ than females $(40.5 \%)$ have been reported by Rai et al., and Ishiyama et al.8, 9 The relation between drinking water source and parasitic infection showed the higher prevalence among the students drinking raw water and least in those drinking both boiled and filtered. The reasons for this might be due to contamination of raw water with soil, sewages, hospital waste. It may also be due to continuous and overuse of the filteres, not changing the filters etc. In the study Giardia lamblia was the most prevalent parasite (56.5\%). Similar result was reported by Mehraj et al.10 Epidemiological surveys on the intestinal parasite infection are important in this country because they reflect sanitary conditions of the community and produce basic data for the control of parasitoids in the future.

Over the last 50 years there had been substantial reduction in child death rates gained in health and disease 
prevention. Despite this improvement there is still a major burden of disease and ill health among this group, particularly in areas such as poor nutrition and intestinal parasitic diseases. An increasing body of literature now demonstrate that there is an association between wide spread conditions such as iron deficiency, iodine deficiency and parasitic helminthes infection and under achievement in school with low scores in test of cognitive ability.

CONFLICT FO INTEREST: None to declare.

FINALCIAL INTEREST: None to declare.

\section{REFERENCES}

1. WHO. World Health Report 2000. Conquering suffering enriching humanity. Geneva; 2000

2. Prasai T, Lekhak B, Joshi DR, Baral MP. Microbiological analysis of drinking water of Kathmandu valley. Scientific World 2007;5:112-114

3. Timilshina M, Dahal I, Thapa B. Microbial assessment of bottled drinking water of Kathmandu valley. Int J Infect Microbiol 2012;1:84-86. DOI: http://dx.doi.org/10.3126

/ijim.v1i2.7399

4. Sharma BK, Rai SK, Rai DR, Choudhary DR. Prevalence of intestinal parasitic infestation in school children in the northeastern part of Kathmandu Valley, Nepal. Southeast Asian J Trop Med Public Health 2004;35:501-505.

5. Gyawali N, Amatya R, Nepal HP. Intestinal Parasitosis in School going children of Dharan Municipality, Nepal. Trop Gastroenterol 2009;30:145-7.

6. Savioli L, Bundy DAP, Tomkins A. Intestinal parasitic infections: a soluble public health problem. Trans R Soc Trop Med Hyg 1992;86:353-4.

7. Escobedo AA, Canete R and Nunez FA. Prevalence, risk factors and clinical features associated with intestinal parasitic infections in children from San Juan y Martínez, West Indian Med J 2008;57:377-82

8. Rai SK, Hirai K, Abe A, Ohno Y. Infectious diseases and malnourished status in Nepal: an overview. Malays J Nutr 2002;8:191-200.

9. Ishiyama S, Rai SK, Ono K, Uga S. Small-scale study on intestinal parasitosis in a remote hilly village in Nepal. J Nepal Med Coll 2003;5:28-30.

10. Mehraj V, Hatcher J, Akhtar S, Rafique G, Beg MA. Prevalence and Factors Associated with Intestinal Parasitic Infection among Children in an Urban Slum of Karachi. PLoS ONE 2008;3:e3680.

\section{Citing this article}

Maharjan R, Timilshina M, Shakya R, Bhattarai S, Bhattarai S, Gurung P. Prevalence of intestinal parasitic infection of kindergarten children. Int J Infect Microbiol 2013;2(3):111-113. 